\title{
Sağglık İletişiminde Yeni Yaklaşımlar: Dijital Medya Kullanımı
}

\author{
New ApproachesInHealthCommunication: Using Digital Media \\ Zekiye TAMER GENCER * \\ Yllmaz DASSLI ** \\ Enis Baha BIÇER $R^{* * *}$
}

ÖZ

Son yıllarda birçok alanda olduğu gibi sağllk alanında da birey davranışlarında değişiklikler gözlenmektedir. Dünyada ve ülkemizde sağllk konusunda yapılan yeni reformlar ve özellikle Türkiye' de özel hastanelerin devlet tarafindan teşvik edilmesi ile sağllk sektörü birçok açıdan yeniden şekillenmiştir. Bu süreç, sağllk konusunda bireylerin bilgiye ulaşımı ve uzman doktor erişimi açısından da devrim niteliğinde yeniliklerle doludur. Internetin aktif kullanıcı sayısının artması bu devrimin temel yapı taşları arasındadır. Sektörel olarak özelleşme kişiye özel hizmet anlamına geldiğinden, internet kullanıcıları hem bireyler hem de sağllk kurumları nezdinde sayıca artış göstermiştir. Internet teknolojisinin birey hayatına getirdiği en büyük kolaylık olarak nitelendirilen sosyal paylaşım ağları sağllk yapılanmasındaki değiş̧imi hızlandıran bir faktör olarak karşımıza çıkmaktadır. Kullanıcıların içerik üretmesine izin veren ve daha önceden üretilen içeriklere ücretsiz erişsim imkanı sunan platformların son derece fazla olduğu sosyal ağlar, insanların her konuda olduğu gibi sağlık konusunda da bilgi edinmek için ilk başvurduğu kaynaklar arasındadır. Ekonomi, bilim başta olmak üzere hemen her konuda bilgiye erişimin mümkün olduğu sosyal ağlarda oluşturulan sağllk içeriklerinin sayısı da giderek artmaktadır. Online sağllk bilgisi arama İnternetteki en yaygın aktiviteler arasına girmiş, yalnızca yazıll bilgi ile sinırl kalmayarak sesli ve video aracıllğıyla görüntülü paylaşımlar da bilgiye ulaşma açısından tercih edilirliğini artırmıştır. Uzmanlar ve doktorlar sağllğın her alanı ile ilgili bireyin ihtiyaç duyacăğ düzeydeki bilgiyi sosyal ağlar üzerinden paylaşmakta ve hatta ilaç kullanımı, alternatif tedavi yöntemleri, destekleyici ürün kullanımı konularında da yönlendirici içerikler üretmektedir. Bütün bunlar birlikte değerlendirildiğinde online iletişim araçlarının geniş bir yelpazesini içeren ve çeşitli mekanizmalarla çalışan sosyal ağlar (sosyal medya), sosyal destek için bir kanal sağlamakta ve bireyler arasında bağlantı duygusunu kolaylaştırmaktadır. Bağlantı kurmadaki sağladığı kolaylık E-sağlık diye tanımlanan yeni bir dijital sağlık platformunu da inşa ederek konuya yeni bir yaklaşım getirmiştir. Bu çalışmada Gencer (2016) tarafindan Türkçe uyarlaması yapılan "E-Okur Yazarlık Ölçeği” kullanılarak üniversite ögrencilerinin sosyal ağları sağlık alaninda kullanma biçim ve düzeyleri tespit edilecektir.

\section{ANAHTAR KELIMELER}

E-Okuryazarlık, Sağlık İletişimi, Sosyal Medya, Dijital Să̆glık

\footnotetext{
* Doç. Dr., Sivas Cumhuriyet Üniversitesi İletişim Fakültesi, zekiye_tamer@hotmail.com, ORCID: 0000-0001-6065-7395

** Dr. Öğr. Üyesi, Sivas Cumhuriyet Üniversitesi Sağlık Bilimleri Fakültesi, ydasli@ hotmail.com, ORCID: 0000-0001-6569-1103

*** Dr. Öğr. Üyesi, Sivas Cumhuriyet Üniversitesi Sağlık Bilimleri Fakültesi, ebbicer@cumhuriyet.edu.tr, ORCID: 0000-0002-1624-4988
} 


\section{ABSTRACT}

Like in many fileds, there have been changes on individual attitutes in health sphere. Thanks to the improvements and renovations in health sector in the World and the promotions of private hospitals in Turkey have reshaped the health sector. This process has let the individuals get the chance of accessing essential information and doctor. The increase in the number of internet users is one of the main reasons of this improvement. As the privatization of the sector provides private service for individuals, the number of the internet user sincrease both individuallyand in terms of heatlh instituations. Social networks which the internet technology brings in to our life are seen as the factors causing the changes of the health sector. The social networks which let people produce content or Access the content produced are the firsts ources that people ask for health. The number of the health contents which are produced on social platforms like many other fields are increasing gradually. Nowadays, people are searching for information for their illness on the internet and apart from this, they start to share records or videos to spread the information. The specialists or doctors share the information that the patients need to get cure for their illness and also they produce contents about the use of remedies, alternative medical treatments and, supportive productuses. Taken all these into consideration together, the social networks that include online communication tools and work with various mechanisms provide a channel for social support and make it easy to build a connection between the individuals. E-health known as a new digital health platform is the outcome of this connection. In this study, universtity students' type and levels of using social networks for health sphere will be determined by using "E-literacy Scale" adapted by Gencer (2016).

\section{KEYWORDS}

E-Literacy, Health Communication, Social Media, Digital Health

\begin{tabular}{|c|c|c|}
\hline \multicolumn{2}{|r|}{$\begin{array}{c}\text { Makale Geliş Tarihi / Submission Date } \\
03.10 .2018\end{array}$} & $\begin{array}{c}\text { Makale Kabul Tarihi / Date of Acceptance } \\
20.02 .2019\end{array}$ \\
\hline Atıf & $\begin{array}{l}\text { Gencer T., Z., Daşl, Y., Biçer, E.B. (2 } \\
\text { Üniversitesi Sosyal Bilimler Meslek Y }\end{array}$ & $\begin{array}{l}\text { e Yeni Yaklaşımlar: Dijital Medya Kullanımı. Selçuk } \\
(1), 42-52\end{array}$ \\
\hline
\end{tabular}




\section{GİRIŞ}

Ekonomi, bilim başta olmak üzere hemen her konuda bilgiye erişimin mümkün olduğu sosyal ağlarda oluşturulan sağlık içeriklerinin sayısı da giderek artmaktadır. Online sağlık bilgisi arama İnternetteki en yaygın aktiviteler arasına girmiş, yalnızca yazılı bilgi ile sınırlı kalmayarak sesli ve video aracılığıyla görüntülü paylaşımlar da bilgiye ulaşma açısından tercih edilirliğini artırmıştır. Uzmanlar ve doktorlar sağlığın her alanı ile ilgili bireyin ihtiyaç duyacağı düzeydeki bilgiyi sosyal ağlar üzerinden paylaşmakta ve hatta ilaç kullanımı, alternatif tedavi yöntemleri, destekleyici ürün kullanımı konularında da yönlendirici içerikler üretmektedir.

Sağlık iletişimi, ilgili alan ile alakalı olarak, son yıllarda sağlık bilgisine ulaşma ve bilgiyi paylaşma açısından yeniliklerle dolu bir çerçevede karşımıza çıkmaktadır. Ülkemizde 2016 yılında Sağlık Bakanlığı tarafından gerçekleştirilen son düzenlemeler ile hasta trafiğinde epeyce artış sağlayan özel hastane yapılanmaları ve kamu hastanelerindeki iyileştirmeler sayesinde hastaların bilinç düzeyinde sağlanan artış bu yeniliklerin temel gerekçelerindendir. Sağlık alanı ile alakalı olan bu değişmeleri yakından takip eden bireyler, şikâyet-memnuniyet gibi duygu ve düşüncelerini de interaktif bir şekilde ilgili taraflar ile paylaşma olanağı bulmaktadır. Bu durumun sebeplerinden biri, hastaneler ve sağlık kuruluşlarının da web tabanlı teknolojiler ile uyum sağlamış olmalarıdır. Birçok farklı alanda olduğu gibi sağlık konusunda da geliştirilen alt yapı çalışmaları sayesinde hem bireysel hem kuruluş (hastane) hem de hekim bilgileri web ortamında kolaylıkla ulaşılabilir hale gelmiştir. Son yıllarda yapılan çalışmalar, online sağlık bilgisi aramanın internetteki en yaygın aktiviteler arasında (Eysenbach, 2008:124) olduğunu ortaya koyarak sağlık alanında yaşanan yenilikleri ve devrimleri doğrular niteliktedir.

Bu bağlamda çalışmanın desteklenmesi amacıyla yapılan araştırmada, sosyal medya ve internet üzerinden sağlık bilgilerine erişme düzeyini belirleyen e-okuryazarlık ölçeği ile üniversite öğrencilerinin, yaş, cinsiyet, sosyal medya kullanım süresi gibi değişkenler arasında anlamlı bir farklılık ve ilişki olup olmadığının tespit edilmesi için çeşitli istatistiksel analizler kullanılarak bir sonuca ulaşılmıştır.

\section{KAVRAMSAL ÇERÇEVE}

Sağlık kuruluşlarındaki kurumsal değişikliklerin yanı sıra bireysel davranış biçimleri de sağlık iletişimi alanında bilgi yayılım düzeyinde farklı yaklaşımların ortaya çıkmasına sebep olmuştur. Çünkü son yirmi yılda küreselleşme hareketi sonucunda birçok farklı alanda son derece hızlı bir değişim yaşanmaktadır. Yaşanan bu değişimin temel noktası da yeni iletişim ve enformasyon teknolojilerindeki gelişmeler (Karagöz, 2013:135) şüphe götürmez bir gerçektir. Bu teknolojik ilerlemenin en temel yapı taş1 olan internetin patlayan büyümesi, yeni bir dijital medya kültürünün gelişimine neden olarak sağlık iletişimi alanında da ezberi bozmaktadır (Montgomery, 2000:65) . Çünkü sağlık konusundaki iletişim, teknolojinin de hızlı deviniminin bir sonucu olarak büyük oranda kitle iletişim araçları üzerinden yapılır duruma gelmiş (Koçak ve Bulduklu, 2010:8) geleneksel yöntemler terk edilmiştir. Artık "E-sağlık" diye ifade edilen yeni bir kavram doğmuş ve bu kavram sayesinde birey, hasta ve uzman davranışları yeniden tanımlanmıştır. Sağlık hizmeti kuruluşları da sosyal medya araçlarını kullanarak kurum ve iletişim bilgilerini, kurum ile ilgili haberleri, fotoğrafları, videoları, sağlık ve sağlı hizmetleri ile ilgili bilgileri ve kullanıcı yorumlarını tüketiciler ile paylaşabilmektedir (Tengilimoğlu vd, 2015:82).

Bütün bunlara paralel olarak gelişen internet teknolojisinin insan hayatına kattığı sosyal ağlar (sosyal medya) da bu devinimin temel tetikleyicisidir. Sosyal medya araçları geleneksel bilgi edinme araçlarından farklı olarak kullanıcı odaklı bir kullanım alanı sunmaktadır. Eskiden tek elden iletilen bilgilerin yerini artık kullanıcı tarafından üretilen içerikler almıştır. Ayrıca, geleneksel iletişim araçları olan televizyon, gazete ve radyo hem iletişim araçlarının sahipliğinde hem de içeriğin belirlenmesinde merkeziyetçi bir yapıya sahip olmakla birlikte, TV istasyonları bir ya da birkaç kişinin sahipliğindeyken, uluslararası alanda tekellerin kontrolündeydi. Ancak, yeni iletişim teknolojileri sayesinde bu hegemonyalar yıkılmaya başlanmış, çeşitlenme ve parçalanma ile kontrol tekeli çok merkezli hale gelmiştir (Karagöz, 2013: 133). Bu çok merkezli yap1 sayesinde hemen her alanda olduğu gibi sağlık alanında da bilgiye erişim çok daha kolay hale gelmiş, içeriklerin artan sayısı ile bireylerin sağlık konusunda enformasyona ulaşma sansı artmıştır.

Sağlık iletişiminde gerçekleştirilen değişikliklerin temelinde yatan sosyal medya ortamlarının etkisi, bu alanda önemli bir bilgi kaynağı haline gelmiştir. Çünkü sosyal medya, katılımcıların birbirleriyle etkileşim kurmalarına, topluluk geliştirmelerine ve bilgi ve fikir paylaşmalarına olanak sağlayan sanal topluluklar veya ağlardır (Al-Bahrani vd, 2017). Bu çevrimiçi araçlar, kullanıcıların, kullanıcı odaklı ve tüketici kontrollü olan bilgileri paylaşmalarına olanak sağlamakta ve büyük izleyici gruplarına uzak veya yakın mesafeler üzerinden ulaşmak için ucuz bir yol olarak kullanılmaktadır. En önemlisi de sosyal medya farklı sosyo-demografik gruplar arasında sağlıklı bilgi alış verişine uygun bir ortam sağlamaktadır. Tüm bu özellikler, sosyal medyayı her alanda olduğu gibi sağlık alanında da içerik paylaşımının teşviki ve geliştirilmesi için çok uygun ve popüler 
araçlar haline getirmektedir. Son yıllarda internet teknolojisinde yaşanan gelişmeler, özellikle Web 2.0 teknolojisine geçilmesi ile erişimi daha kolay ve daha ucuz hale gelen internetin dünya genelinde kullanımının artması sosyal medya kullanımını da artırarak geniş hedef kitleler arasında paylaşım yapılmasına olanak sağlamaktadır (Tengilimoğlu vd, 2015:79). Facebook, Twitter, Instagram başta olmak üzere farklı birçok platform üzerinden paylaşım olanağı sunan sosyal medya araçlarının gelişimi son on yıla dayanmaktadır. AlBahrani (2017) tarafindan tanımlanan sosyal medya araçlarının özellikleri şu şekildedir: Facebook kullanıcıların profil oluşturduğu ve diğer kullanıcılarla "arkadaş" haline gelmelerini sağlayan bir sosyal medya platformudur. Arkadaşlar birbirleriyle "durum güncellemeleri" ve özel mesajlar aracıllğıyla video, resim ve bağlantıları paylaşabilmektedir. Kullanıcılar ayrıca gruplar, "özel sayfalar" ve etkinlik sayfaları da oluşturabilmektedir. Benzer şekilde, Twitter da kullanıcıların diğer "kullanıcılar" ile iletişimine izin veren bir ağdır ve onlarla kamuya açık veya özel paylaşımlarla iletişim kurmalarına olanak tanımaktadır. Ancak, en büyük fark Twitter'ın kısa mesaj kullanımı gerektiren metin büyüklügünün 140 karakter ile kısıtlı olması idi ancak bu kısıt artık yayıncı tarafından kaldırılarak 280 karakter şeklinde güncellenmiştir. Instagram, kullanıcıların resim veya 15 saniye veya daha az sürede kendi ağları ile videoları paylaşmasına olanak sağlamaktadır. Instagram'daki mesajlar, Facebook ve Twitter gibi sosyal medya siteleriyle de aynı anda paylaşılabilmektedir(Al-Bahrani vd,2017). Bu ağlar arasındaki ortak paylaşım da kullanım açısından zengin bir platform sağlamaktadır. Özellikle son birkaç yıl içinde, Facebook, YouTube, Twitter ve diğer sosyal medya araçlarının sağlık mesajları yaymak için kullanımı önemli derecede artmıştır ve yükseliş trendi devam etmektedir (Şener ve Samur, 2013:513). Mesela 2010da kurulduğu günden bugüne 700 milyondan fazla (Instagram,2018) kullanıcıya erişmesi bu artan trendin bir kanıtıdır.

Yapılan araştırmalara göre, birçok yetişkin (hala) internetten daha çok hekimlerine güvenmektedir, birçok durumda internet, bilgi danışılan ilk kanaldır (Eysenbach, 2008:125). Bu durum sadece yetişkinlerde değil çocuk ve gençlerde de aynı şekildedir. Eysenbach, yetişkinlerin genellikle internetten tedaviler veya hastalıklarla ilgili tıbbi bilgi edinirken, gençlerin sağlıkla ilgili (ör. Fitness, diyet) veya cinsellikle ilgili bilgi arama olasılıklarının daha yüksek olduğunu belirtmektedir. Ayrıca gençlerin, yetişkinlerden daha çok dijital medya yoluyla daha fazla bilgiye eriştiğine dair kanıtlar vardır ve bu bulguların yetişkinlerle karşılaştırıldığında daha doğal bilgi bulmak için bu araçları kullanarak bulabileceklerini düşündürmektedir (Flanagin ve Metzger, 2008:12). Bu teknoloji, çocukların hayatına da derinlemesine gömülmüş (Smahel ve Cernikova, 2015:134) olduğundan çocukluk döneminde de paylaşımlar ve sağlık konusunda bilgi edinme çabaları açısından sosyal medya artan bir düzeyde kullanıma sahiptir. Özellikle Instagram üzerinden hastalık, tedavi ve alternatif tıbbi yöntemlerle ilgili yapılan paylaşımların sayısı göz önüne alındığında hekimleri tekil ziyaret eden birey sayısından daha büyük bir kitlenin sosyal medyada olduğu söylenebilmektedir. Karimkhani ve arkadaşları tarafindan 2014 yılında yapılan bir çalışmada Instagram üzerinden gençlerin en sık yaptığ1 hashtag (etiket) aramalar ile Türkçe dilinde aynı kelime ile yapılan aramalar karşılaştırılmıştır. Tabloda görüldüğü gibi hem İngilizce hem de Türkçe olarak cilt, akne gibi gençlerin sık arama yaptığı kelimelerin aranma düzeyi oldukça yüksektir. Bu da gençlerin sağlıkla ilgili bilgi edinme noktasında sosyal medya araçlarını kullandığının bir kanıtıdır. Bunun dışında yapılan araştırmalara göre, bir günde, çocukların \% 75'i ortalama 1 saat 20 dakika boyunca televizyon izlemiş ve \% 32 si video / DVD'leri izlemiştir. Yeni medyanın küçük çocuklar düzeyindeki durumu ise: 5 ila 6 yaşındaki çocukların \% 27'si bir günde (ortalama 50 dakika boyunca) bir bilgisayar kullanmıştır (Vandewater vd, 2007:1009). Bu araştırma sonucunda elde edilen veriler ve yorumları da çocukluk çağlarından itibaren dijital araçların kullanıldığı gerçeğini ortaya çıkarmaktadır. 
Tablo 1. Dermatolojik Hastalıklarla İlgili En Çok Aranan "Hashtags" Ve Gönderi Sayılarının 2014 ve 2018 Karşılaştırılması

\begin{tabular}{llll}
\hline Skin & $10.043,312$ & Cilt & 775.834 \\
\hline Acne & $2.205,089$ & Akne & 87.141 \\
\hline Eczema & 506.234 & Egzama & 49.193 \\
\hline Alopecia & 375.490 & Saç dökülmesi & 57.014 \\
\hline Psoriasis & 346.019 & Sedef hastalığ & 4.407 \\
\hline Accutane & 53.965 & Accutane & 53.965 \\
\hline Dermatologist & 202.483 & Dermatolog & 31.943 \\
\hline Melanoma & 79.857 & Melanoma & 79.857 \\
\hline
\end{tabular}

Yukarıdaki tabloda görüldüğü gibi, internet ortamında farklı dillerde yapılan arama sayılarındaki artış, bireylerin sağlı hizmetini alacağı hekim ve kuruluş hakkında bilgi toplama düzeyinin yükseldiğini; tüketicinin sağlık hizmeti alma kararını bu bilgi toplama sürecinin sonunda vererek muayene, teşhis ve tedavi sürecine başlamakta olduğunu göstermektedir (Tengilimoğlu vd, 2015:84). Çünkü artık E-sağl1k şeklinde tanımlanan bu yaklaşım, yeni iletişim teknolojilerinin tüm işlevlerinin hizmete sunularak, hastaların tedavisinde, sağlık hizmetlerine çabuk ve kolay ulaşılmasında, sağlı sektöründe yer alan tüm paydaşlara nitelikli, verimli ve etkili hizmetlerin sunumunda (Aygün, 2007:292) sosyal medyanın kullanılmasını kaçınılmaz hale getirmektedir. Korda ve Itani'nin (2013) de belirttiği gibi, toplumsal kitlelere ulaşmada etkinliklerini gösteren kanıtlar oluştuğundan, sosyal medya sağlığın teşviki ve geliştirilmesinde tercih edilen yöntem haline gelmiştir. Çünkü sosyal medya teknolojileri; toplumsal ilişkilerin bir parçası olarak gelişme göstermekte olup katılımcı ve anti otoriter organizasyon yapısı ve ana akım medyada (TV-Radyo-Gazete) görmeye alışık olunmayan aktörler ile onların sorunlarının içeriğinde yer alması olarak saptanmaktadır (Türk, 2013:55). Geleneksel haber medyası sağlık altyapısındaki detaylı bilgi erişimine yardımcı olmasına rağmen rapor ettikleri ve paylaştıkları bilgiler internette oluşturulan kamuoyundan edinilebilecek potansiyel kolektif haberlere k1yasla daha geride kalmaktadır. Örneğin, Amerikalıların tahminen \% 37-52'si internette her y1l sağlıkla ilgili sosyal medyadan bilgi aramakta, genellikle koşullar, belirtiler ve tedaviler konusunda tavsiyeler bulmak için arama motorlarını kullanmaktadır (Brownstein vd, 2009).Bunun dışında 2008 y1lı sonunda, ABD'de yetişkinlerin neredeyse \%74'ü, internete girmiş (Fox ve Jones, 2009) ve sağlık alanında bilgi araması yapmıştır.

Bütün bu gelişmeler birlikte değerlendirildiğinde, sağlık iletişimi alanında, internet teknolojilerindeki (Web 2.0) son gelişmelerin, özellikle katılımcı internet'in (sosyal medya olarak da bilinir) gelişmesiyle, sağlıkla ilgili iletişimler de dahil olmak üzere iletişim örüntüsünü dönüştürdüğüne dair yaygın bir varsayımdan (Chou vd, 2009) bahsetmek mümkündür. Mobil cihazların kullanılması da sağlı alanındaki yeni yaklaşımların oluşmasının ve sağlık iletişimin teşvik edilerek geliştirilmesine yönelik çabalarda önemli bir değişimin temsili (Lupton, 2012:230) anlamına gelmektedir. Mobil cihazların alt yapı itibariyle çevrimiçi sosyal medya araçlarına son derece kolay ve hızlı bir erişim sağlıyor olması bunun temel sebebidir. Mobil cihazlar üzerinden erişim sağlayan sağ $ı$ ğın teşviki ve geliştirilmesi alanındaki profesyoneller, sosyal medyanın sosyal pazarlama kampanyalarıyla geniş kitlelere ulaşma potansiyelini tanımakta ve tüketicileri sağlık ve sağlıkla ilişkili etkileşimlerinde güçlendirmek için çabalamaktadır (Thackeray vd, 2008). Bu bağlamda Becerikli (2012)'nin sağlık iletişiminde kullanılan yöntemleri sosyal pazarlama, medyada savunuculuk ve halkla ilişkiler olarak özetlediği çalışmasında, sağlık iletişimi alanında yapılan iletişim kampanyalarının, hepsinde olmasa da, tipik karakteristik özellikleri şu şekilde sıralanmaktadır (Akt.: Okay, 2007: 118):

- İletişim kampanyaları bir sağlık davranışını edinmesi ve değiştirmesi beklenen kişiler için doğrudan eğitim sağlamayı amaçlar.

- Kampanyalar geniş kitleleri etkilemeyi hedefler ve değerli kaynakları göreve dahil ederler (bunlar parasal, gönüllülük temelinde ya da başka kurumlarla işbirliği şeklinde olmaktadır)

- Kampanyalar sıklıkla çoklu kanalları kullanırlar ve araçlı kanalları (televizyon, radyo) kişisel kanallarla (sağlık profesyonelleri, sosyal yardım çalışanları) bütünleştirirler.

- Kampanyalar tüketicilerin davranış hakkında ne bildikleri, neye inandıkları ve/veya güncel ve/veya algılanan sosyal normları etkileyerek önerilen davranışların kabul edilmesini etkilemeye çalışırlar. 
- Kampanyalar önerilen davranışların kabulünü, tüketicilerin davranış hakkında neye inandıklarını ve neyi bildiklerini, gerçeği ve algılanan sosyal normları etkileyerek, (öz yeterlilik) yeteneklere güvenerek ve gerçek yetenekleri değiştirerek etkilemeye çalışırlar. Bunların tümünün davranışı etkilediği varsayılır.

- Kampanyalar genellikle hükümetler tarafından desteklenmektedir. Bazen bu destekler özel şirketler ve profesyonel organizasyonların işbirliğiyle veya ulusal taraflar ve profesyonel organizasyonlar tarafindan tek başına da gerçekleşebilmektedir.

- Kampanyalar sıklıkla daha geniş bir sosyal pazarlama programının unsurudur. Sosyal pazarlama, ticari pazarlama fikirlerinin, sosyal ve sağlıkla ilgili sorunları çözmeye yardımcı olacak şekilde uygulanmasidir.

İletişim önemli bir bilgi ve tecrübe aktarım yöntemidir. İletişimin hangi tür ve yöntemi olursa olsun bireyler arasında ve toplumda bir konu hakkında yoğun bilgilendirme ile genel bir kanaat oluşması sağlanabilmektedir. Bu sebeple, sağlık ve hastalık da iletişim insan deneyimlerinin en hayati boyutunu oluşturmaktadır (Koçak ve Bulduklu,2010:7). Bu bakış açısıyla dijital iletişimin, sağlık alanında önemli bir devrimsel nitelikte rolü olduğunu söylemek mümkündür. Özellikle sosyal medya ile yaygın halk katılımının, sağlık alanında sağlanması için hazır bir platform oluşturulmaktadır. Hem profesyoneller hem de tekil kullanıcıları bir araya getiren bu platformların sağlık bilgisi açısından farklı olmasının son nedenini Eysenbach (2008) şöyle ifade etmektedir: "İçeriğin ve güvenilirliğin değerlendirilmesine yardımcı olan ipuçları ayrı olarak verilebilmektedir ve her ikisi de dinamik olarak ve akullica bireye uyarlanabilmektedir; Internet bir gazete, kitap ya da hasta broşürü gibi statik bir araç değildir, burada bir kişi yanlış bilgi aldığında, sağllk çalı̧̧anlarının bilgileri düzeltmek için yapabilecekleri çok az şey vardır".

\section{ARAŞTIRMA VE YÖNTEM}

Üniversite öğrencilerinin elektronik düzeyde sağlık okuryazarlığı seviyelerinin tespit edilmesini amaçlayan araştırma yapılmadan önce pilot uygulama olarak anket formunda bulunan soruların net ve anlaşılır olup olmadığının belirlenmesi için 50 üniversite öğrencisi ile bir ön test yapılmıştır. Burada asıl amaç soruların anlaşılırlığını tespit etmek, anlaşılmayan ve kafa karışıklığı yaşatan soruların anket formundan çıkarılmasını veya yeniden düzenlenmesini sağlamaktır. Yapılan pilot araştırmadan sonra gerekli görülen düzeltmeler anket formu üzerinde gerçekleştirildikten sonra 1 Mart-1 Nisan 2018 tarihleri arasında Cumhuriyet Üniversitesi merkez kampüsünde araştırma yüz yüze anket tekniği kullanılarak yapılmıştır. Araştırmanın evreni Cumhuriyet Üniversitesi'nde eğitim-öğretim gören lisans öğrencileri oluşturmakta olup, basit tesadüfi örnekleme yöntemi ile 420 kişi örnekleme alınmıştır. Araştırma evreninin kısıtı Cumhuriyet Üniversitesi'nde lisans öğrenimi gören öğrencilerdir ve ilgili tarih aralığında geçerli sonuçlara sahip kesitsel bir araştırmadır.

Oluşturulan anket formu üç bölümden oluşmaktadır. Birinci bölüm: Öğrencilerin demografik bilgileri, ikinci bölüm: İnternet ve sosyal medya kullanma süreleri ve amaçları ve üçüncü bölüm: 5'li likert sorularından oluşan (1- Tamamen Katılmıyorum; 2-Katılmıyorum; 3-Kararsızım; 4-Katılıyorum ve 5- Tamamen Katılıyorum) E- sağlık okuryazarlığ ölçeği şeklindedir. Bu ölçek, 2017 yılında İstanbul Üniversitesi İletişim Fakültesi Dergisinde Zekiye TAMER GENCER tarafından yayınlanan "Norman Ve Skınner'ın E-Sağlık Okuryazarlığı Ölçeğinin Kültürel Uyarlaması İçin Geçerlilik Ve Güvenilirlik Çalışması” adlı çalışmasındaki sağlık okuryazarlığını ölçmektedir. Elde edilen veriler SPSS 23.0 programı kullanılarak analiz edilmiştir.

Araştırmada, sosyal medya ve internet üzerinden sağlık bilgilerine erişme düzeyini belirleyen eokuryazarlık ölçeği ile üniversite öğrencilerinin, yaş, cinsiyet, sosyal medya kullanım süresi gibi değişkenler arasında anlamlı bir farklılık ve ilişki olup olmadığının tespit edilmesi amacıyla çeşitli istatistiksel analizler kullanılmıştır. Araştırma soruları şöyledir:

1. Üniversite öğrencilerinin sosyal medya kullanım sıklı̆̆ı nedir?

2. Üniversite öğrencilerinin sosyal medya kullanım motivasyonları nelerdir?

3. Üniversite öğrencilerinin sosyal medya üzerinden să̆lık kaynaklarına erişim düzeyi nedir?

4. Üniversite öğrencileri sosyal medya aracılığı ile sağlık kaynaklarına erişme ve kaynakları kullanma konusunda yeterliliğe sahip midir?

\section{BULGULAR VE YORUM}

Araştırma sonucunda elde edilen verilere ait yorumlar şu şekildedir; 
Tablo 2. Çalışmaya katılan öğrencilerin demografik bilgileri

\begin{tabular}{|c|c|c|c|}
\hline & & Frekans & Yüzde \% \\
\hline \multirow{3}{*}{ Cinsiyet } & Kadın & 314 & $\% 74,8$ \\
\hline & Erkek & 106 & $\% 25,2$ \\
\hline & Toplam & 420 & $\% 100,0$ \\
\hline \multirow{5}{*}{ Yaş } & $18-21$ yaş & 226 & $\% 53,8$ \\
\hline & $22-25$ yaş & 186 & $\% 44,3$ \\
\hline & $26-29$ yaş & 4 & $\% 1,0$ \\
\hline & 30 yaş ve üzeri & 4 & $\% 1,0$ \\
\hline & Toplam & 420 & $\% 100,0$ \\
\hline \multirow{5}{*}{ Çoğunlukla Yaşanan Yer } & Koy & 76 & $\% 18,1$ \\
\hline & İlçe & 118 & $\% 28,1$ \\
\hline & İl & 136 & $\% 32,4$ \\
\hline & Büyük şehir & 90 & $\% 21,4$ \\
\hline & Toplam & 420 & $\% 100,0$ \\
\hline \multirow{6}{*}{ İkamet Yeri } & Ailemle & 140 & $\% 33,3$ \\
\hline & Arkadaşlarımla & 30 & $\% 7,1$ \\
\hline & Yalnız & 12 & $\% 2,9$ \\
\hline & Yurt & 234 & $\% 55,7$ \\
\hline & Diğer & 4 & $\% 1,0$ \\
\hline & Toplam & 420 & $\% 100,0$ \\
\hline \multirow{3}{*}{ Akıllı Telefon Sahipliği } & Evet & 420 & $\% 100,0$ \\
\hline & Hayır & 0 & $\% 0$ \\
\hline & Toplam & 420 & $\% 100,0$ \\
\hline \multirow{8}{*}{ İnternete Bağlanılan Yer } & Okuldan & 8 & $\% 1,9$ \\
\hline & Evden & 64 & $\% 15,2$ \\
\hline & Yurttan & 220 & $\% 52,4$ \\
\hline & Internet kafeden & 2 & $\% 0,5$ \\
\hline & Is yerinden & 2 & $\% 0,5$ \\
\hline & Cepten & 122 & $\% 29,0$ \\
\hline & Diğer & 2 & $\% 0,5$ \\
\hline & Toplam & 420 & $\% 100,0$ \\
\hline
\end{tabular}

Araştırmaya katılan 420 öğrencinin \%74,8'i kadın, \%25,2'si erkek öğrenciden oluşmaktadır. $\mathrm{Bu}$ öğrencilerin yaş dağılımı ise, 18 ve 31 yaş arasında değişmektedir. \%53,8'i 18-21 yaş, \%44,3'ü 22-25 yaş, \%1,0'i 26-29 yaş ve \%1'i 30 yaş ve üzeri öğrencilerden oluşmaktadır. Araştırmaya katılan öğrenciler üniversitenin sosyal, fen ve sağlık olmak üzere tüm alanlarında eğitim gören öğrencilerden olmak üzere eşit şekilde dağılım göstermektedir. Ankete katılan öğrencilerin en çok yaşadıkları yer $\% 32,4$ şehir, $\% 28,1$ ilçe, \%21,4 büyükşehir ve kalan \%18,1 de köy şeklindedir. Şu an ikamet edilen yer sorusuna ankete katılan öğrenciler şu şekilde cevap vermiştir; $\% 55,7$ yurt, $\% 33,3$ aile ile birlikte, $\% 7,1$ arkadaşlar ile evde, $\% 3,9$ yalnız yaşamakta. Bu öğrencilerin haber alma ve bilgiye erişim için en sık kullandıkları araçlar \%88,1 internet, \%7,1 televizyon, $\% 2,4$ gazete, $\% 1,4$ dergi ve $\% 1$ insanlar şeklindedir. Burada internetin yeni bilgi paylaşım aracı olduğu çarpıcı bir şekilde görülmektedir. Ankete katılanların internet bağlantısına ulaştıkları yerler de; \%52,4 yurttan, \%29,0 cep telefonundan, \%15,2 evden, \%1,9 okuldan şeklindedir. Burada dikkat çeken sonuçlardan biri olan cep telefonu ile internete bağlanma oranıdır. Katılımcı cevaplarında da akı1lı telefon sahipliği \%100 ve cep telefonu ile internete bağlanma oranı \%99,0 olarak görülmüştür. Ayrıca katılımcıların \%38,8'i günde 1-3 saat, \%42,9' u 4-6 saat, \%12,9'u 7-9 saat, \%6,7'si 10-12 saat ve \%2,9'u 13 saat ve üzerinde internete bağlanmaktadır. İnterneti kullanım amacı sorusuna tek seçenek işaretleyerek yanıt vermeleri istenen öğrencilerin cevap dağılımları şu şekildedir; \%31,0 İletişim ve posta, \%60 sosyal medyaya erişim, \%5,7 eğitim/araştırma, \%1,4 haber alma ve $\% 1,9$ oyun/eğlence. Ankete katılanların $\% 57,1$ 'i günde 1-3 saat, $\% 30,5$ ' i 4-6 saat, \%6,7' si 7-9 saat, \%3,8'i 10-12 saat ve \%1,9'u 13 saat ve üzerinde sosyal medya araçlarına bağlantı gerçekleştirmektedir. Bu sonuçlara göre araştırmaya katılan öğrencilerin gün içerisinde sosyal medyayı sık bir şekilde kullandıkları görülmektedir. En sık kullanılan sosyal medya araçları ise sırasıyla, \%69,5 Instagram, $\% 16,2$ WhatsApp, \%5,7 Facebook, \%5,7 Twitter ve \%2,9 Youtube şeklindedir. Bu çalışmada da dünyada ve Türkiye'de en sık kullanılan araç olan Instagram üzerinden sağlık paylaşımları tablo olarak verilmiş ve bu mecranın sağlık paylaşımlarında son yıllarda büyük bir artış gözlemlenmiştir.

Anketin ikinci kısmında sağlı iletişimi bağlamında internet kullanım motivasyonlarını incelemek için sorulan iki farklı sorudan da öğrencilerin bu konuda dijital araçlara olan eğilimi gözlenmektedir. "Sağlı̆̆ınız hakkında karar verirken internetin size yardımcı olmada ne kadar faydalı olduğunu düşünüyorsunuz" sorusuna, $\% 55,2$ yararlı, \%8,1 çok yararlı, \%17,1 fikrim yok, \%14,3 yararlı değil ve \%5,2 hiç yararlı değil 
şeklinde cevaplar verilmiştir. "İnternette sağlık kaynaklarına erişebilmek sizin için ne kadar önemli”" sorusunun cevap dağılımı ise şu şekildedir, \%57,6 önemli, \%15,7 çok önemli, \%12,9 fikrim yok, \%11,45 önemli değil ve \%2,4 hiç önemli değil. Bu cevap dağılımları ankete katılan üniversite öğrencilerinin sosyal medya araçlarını sağlı iletişim açısından da etkili bir biçimde kullandıklarını göstermektedir.

E- okuryazarlık ölçeğinde bulunan 8 maddelik soruların cevap dağılımları tablodaki (Tablo 3) gibidir. İnternette bulunan sağlı kaynaklarına erişim, yararlı sağlık kaynaklarını bulma, kaynakların nasıl kullanılacağı, sağlık hususunda yanıt bulmak için kaynakların kullanımı, sağlık bilgilerini kullanma, değerlendirme becerisi, kaynak kalitesi ve kendine güven ifadelerini ölçen soruların yanıtları yüksek oranda olumlu (katılıyorum/tamamen katılıyorum) yanıtlar almıştır. Bu da ankete katılan öğrencilerin sağlık iletişimi alanında dijital kaynak kullanımının üst düzeyde olduğu göstermekte olup çalışmaya katılan 420 öğrenciden 252 kişisi sağlıkla ilişkili karar vermesi gerektiği durumlarda internetten bilgi kullanımında kendisine güvenmektedir.

Tablo 3. E-Okur-yazarlık ölçeği faktör ifadelerine katılım düzeyleri

\begin{tabular}{|c|c|c|c|c|c|c|}
\hline $\begin{array}{l}\text { E-Okuryazarlı̈Ölçeğiliffadeleri } \\
\text { (f ve } \% \text { değerleri)* }\end{array}$ & 导 & 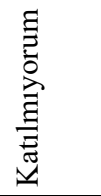 & 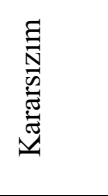 & 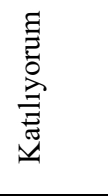 & 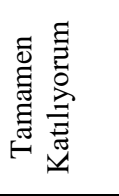 & $\sum_{\substack{1 \\
ٍ}}$ \\
\hline $\begin{array}{l}\text { Internettehangi sağlık kaynaklarının ulaşılabilir } \\
\text { olduğunu biliyorum. }\end{array}$ & $\begin{array}{l}30 \\
\% 7,1\end{array}$ & $\begin{array}{l}40 \\
\% 9,5\end{array}$ & $\begin{array}{l}132 \\
\% 31,4\end{array}$ & $\begin{array}{l}190 \\
\% 45,2 \\
\end{array}$ & $\begin{array}{l}28 \\
\% 6,7\end{array}$ & $\begin{array}{l}420 \\
\% 100\end{array}$ \\
\hline $\begin{array}{l}\text { Internetteki yararlı sağlık kaynaklarını nerede } \\
\text { bulacağımı biliyorum. }\end{array}$ & $\begin{array}{l}22 \\
\% 5,2\end{array}$ & $\begin{array}{l}46 \\
\% 11,0\end{array}$ & $\begin{array}{l}130 \\
\% 31,0\end{array}$ & $\begin{array}{l}200 \\
\% 47,6\end{array}$ & $\begin{array}{l}22 \\
\% 5,2\end{array}$ & $\begin{array}{l}420 \\
\% 100\end{array}$ \\
\hline $\begin{array}{l}\text { Internetteki yararlı sağlık kaynaklarını nasıl } \\
\text { bulacağımı biliyorum. }\end{array}$ & $\begin{array}{l}20 \\
\% 4,7 \\
\end{array}$ & $\begin{array}{l}40 \\
\% 9,5 \\
\end{array}$ & $\begin{array}{l}106 \\
\% 25,2 \\
\end{array}$ & $\begin{array}{l}218 \\
\% 51,9\end{array}$ & $\begin{array}{l}36 \\
\% 8,6 \\
\end{array}$ & $\begin{array}{l}420 \\
\% 100 \\
\end{array}$ \\
\hline $\begin{array}{l}\text { Sağlık hususunda sorularıma yanıt bulmak adına } \\
\text { interneti nasıl kullanacağımı biliyorum. }\end{array}$ & $\begin{array}{l}22 \\
\% 5,3\end{array}$ & $\begin{array}{l}28 \\
\% 6,7\end{array}$ & $\begin{array}{l}80 \\
\% 19,0\end{array}$ & $\begin{array}{l}236 \\
\% 56,2\end{array}$ & $\begin{array}{l}54 \\
\% 12,9\end{array}$ & $\begin{array}{l}420 \\
\% 100\end{array}$ \\
\hline $\begin{array}{l}\text { Internette bana yardımcı olması adına bulduğum } \\
\text { sağlık bilgilerini nasıl kullanacağımı biliyorum. }\end{array}$ & $\begin{array}{l}34 \\
\% 8,1\end{array}$ & $\begin{array}{l}28 \\
\% 6,7\end{array}$ & $\begin{array}{l}94 \\
\% 22,4\end{array}$ & $\begin{array}{l}224 \\
\% 53,3\end{array}$ & $\begin{array}{l}40 \\
\% 9,5\end{array}$ & $\begin{array}{l}420 \\
\% 100\end{array}$ \\
\hline 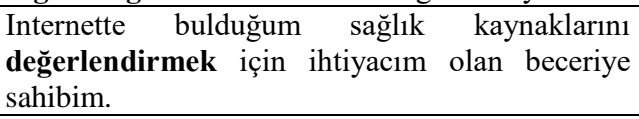 & $\begin{array}{l}20 \\
\% 4,8\end{array}$ & $\begin{array}{l}30 \\
\% 7,1\end{array}$ & $\begin{array}{l}100 \\
\% 23,8\end{array}$ & $\begin{array}{l}212 \\
\% 50,5\end{array}$ & $\begin{array}{l}58 \\
\% 13,8\end{array}$ & $\begin{array}{l}420 \\
\% 100\end{array}$ \\
\hline $\begin{array}{l}\text { Internetteki yüksek kalitedeki sağlık kaynaklarını } \\
\text { düşük kalitedeki sağlık kaynaklarından ayırt } \\
\text { edebilirim. }\end{array}$ & $\begin{array}{l}28 \\
\% 6,7\end{array}$ & $\begin{array}{l}44 \\
\% 10,5\end{array}$ & $\begin{array}{l}114 \\
\% 27,1\end{array}$ & $\begin{array}{l}174 \\
\% 41,4\end{array}$ & $\begin{array}{l}60 \\
\% 14,3\end{array}$ & $\begin{array}{l}420 \\
\% 100\end{array}$ \\
\hline $\begin{array}{l}\text { Sağlığa ilişkin kararlar verirken internetten bilgi } \\
\text { kullanımında kendime güveniyorum. }\end{array}$ & $\begin{array}{l}32 \\
\% 7,6\end{array}$ & $\begin{array}{l}24 \\
\% 5,7\end{array}$ & $\begin{array}{l}112 \\
\% 26,7\end{array}$ & $\begin{array}{l}190 \\
\% 45,2\end{array}$ & $\begin{array}{l}62 \\
\% 14,8\end{array}$ & $\begin{array}{l}420 \\
\% 100\end{array}$ \\
\hline
\end{tabular}

*Verilerin olduğu hücrelerde üstte frekans değerleri altta yüzde değerleri görülmektedir.

\section{1.Ölçek Maddeleri ve Değişkenlerin Analizi}

Araştırmada kullanılan kültürel uyarlaması yapılmış e-okur yazarlık ölçeğinin 8 maddeden oluşan tek faktörlü yapısından elde edilen skor puanları değişkenlerin analizinde yapılan normallik testi sonucuna göre, Bağımsız Örneklem $t$ - Testi (Independent-Samplest-testi) ve Pearson Korelasyon Katsayısı analizleri kullanılarak sonuçlara ulaşılmıştır. Analizler için elde edilen skor puanı hesaplamasında $1=$ Hiç katılmıyorum, 2= Katılmıyorum, 3= Fikrim yok, 4= Katıllyorum ve 5= Tamamen katılıyorum şeklinde hesaplama yapılmıştır.

Tablo 4. Faktör Skor Puanı ve Cinsiyet Grupları Arasında Bağımsız Örneklem T-Testi Sonuçları

\begin{tabular}{|c|c|c|c|c|c|c|c|}
\hline Faktörler & Cinsiyet & $N$ & $\bar{X}$ & $S S$ & $t$ & $d f$ & $p$ \\
\hline \multirow[t]{2}{*}{ Skor Puanları } & Kadın & 314 & 27,99 & 5,96 & 0,3332 & 188,552 & 0,740 \\
\hline & Erkek & 106 & 27,77 & 5,69 & & & \\
\hline
\end{tabular}

Ankete katılan öğrencilerin sosyal medya üzerinden sağlık bilgilerine erişim ve kullanma noktasında tutumları ile cinsiyet değişkeni arasında anlamlı bir farklılık olup olmadığının belirlenmesi için yapılan bağımsız örneklem $t$-Testi ( Independent-Samplest- test) sonucuna göre anlamlı bir farklılık bulunmamaktadır $(\mathrm{t}=0,332 ; \mathrm{p}=0,740>0.05)$. Yani cinsiyetin kadın veya erkek olması dijital araçlar üzerinden sağlık bilgilerini araştırmayı etkilememektedir. 
Tablo 5. Faktör skor puanı ve yaş arasında pearson korelasyon analizi sonuçları

\begin{tabular}{clcc} 
& & Yaş & Skor \\
\hline \multirow{3}{*}{ Yaş } & PearsonCorrelation & 1 &, $162^{* *}$ \\
& Sig. (2-tailed) & &, 001 \\
\multirow{4}{*}{ Skor } & N & 420 & 420 \\
& PearsonCorrelation &, $162^{* *}$ & 1 \\
& Sig. (2-tailed) &, 001 & \\
& N & 420 & 420
\end{tabular}

Araştırmaya katılanların yaşları ile sosyal medya üzerinden sağlı bilgilerine erişim ve kullanma noktasında tutumları arasında anlamlı bir farklılık olup olmadığının tespit edilmesi için, ifadelerin katılım ortalamalarını karşılaştıran Korelasyon Analizi testi yapılmıştır. Korelasyon analizi sonuçlarına göre araştırmaya katılanların yaşları ile sosyal medya üzerinden sağlık alanında erişime yönelik motivasyonlarına ait faktörlerdeki maddeleri değerlendirmeleri bakımından anlamlı bir farklılık olduğu görülmektedir $(\mathrm{p}=0,001<0.05) . \mathrm{Bu}$ farklı1ık veri ortalamaları kıyaslanmak suretiyle incelendiğinde yaşı kısmen daha genç olan katılımcıların daha yoğun sosyal medya erişimi sağlamaları dikkat çekmektedir.

Tablo 6.Faktör skor puanı ve sosyal medyada geçirilen süre arasında pearson korelasyon analizi sonuçları

\begin{tabular}{llcc} 
& & & $\begin{array}{r}\text { Günlük } \\
\text { Sosyal Medyada } \\
\text { Geçirilen Süre }\end{array}$ \\
\hline Skor & PearsonCorrelation & 1 &, 710 \\
& Sig. (2-tailed) & &, 725 \\
Günlük Sosyal & N & 420 & 420 \\
Medyada Geçirilen & PearsonCorrelation &, 710 & 1 \\
Süre & Sig. (2-tailed) &, 725 & \\
\hline & N & 420 & 420 \\
\hline
\end{tabular}

Araştırmaya katılanların günlük sosyal medyada geçirdikleri süre ile sosyal medya üzerinden sağlık alanında erişime yönelik motivasyonları arasındaki ilişkinin ne yönde olduğu ve anlamlı olup olmadığı Pearson Korelasyon Katsayısı analizi ile test edilmiş $(\mathrm{p}=0,725<0,05)$ ve değişkenler arasında anlamlı bir fark olduğu tespit edilmiştir. Korelasyon katsayısının mutlak değerinin 0.70-1.00 arasında olması yüksek bir ilişkinin olduğunu gösterdiğinden burada $(0,710)$ da ilişkinin yüksek olduğu söylenebilmektedir. Sonuç olarak sosyal medyada geçirilen sürenin uzun ya da kısa olması sağlık kaynaklarına erişim ve etkin kullanma düzeyi üzerinde rol oynamaktadır.

\section{SONUÇ VE TARTIȘMA}

Sosyal medyanın, tekil kullanıcılar açısından hastalıkları ve sorunları konusunda bilgi edinmek ve araştırma yapmak amacıyla kullanılmasının yanı sıra sağlık profesyonelleri açısından; klinik araştırmalar/denemeler için denek bulma, sağlık uzmanları için eğitim ve profesyonel gelişim, profesyoneller arası iletişim ve koordinasyon, eğitim simülasyonları; sağlık konusundaki diğer sosyal ağlar, sağlık ve hastalık destek grupları; sağlık savunuculuğu ve sağlık organizasyonları için bağış; popüler sosyal medya platformlarına eklentilerin ve kişisel yönetim araçlarının geliştirilmesi; halk sağlığı konusunda mesajların yayılması; bulaşıcı hastalıkların izlenmesi gibi farklı amaçlar için kullanılması da söz konusudur. Hastalarıyla her tür yolla iletişim kurmak adına bu ağları kullanan sağlık profesyonellerinin hastalardan farklı olarak daha doğru içeriklerle kullandığı gözlemlenmektedir. Bu araştırma sonuçları ve literatür taraması kapsamında bu çalışmada belirtilen diğer alan araştırmaları (Brownstein vd, 2009; Fox ve Jones, 2009; Tengilimoğlu vd, 2015; Türk, 2013; Aygün, 2007; Thackeray vd, 2008; Lupton, 2012; Chou vd, 2009) benzer durumun hastalar açısından da geçerli olduğunu göstermektedir. Bunun yanı sıra hastaya erişim ve tercih edilebilir olma amacıyla özel hasta bilgilerini de içeren sosyal medya gönderilerini kullanan fazla sayıda sağlık profesyonelleri örneğine Türkiye'de de rastlamak mümkündür. Hem hasta hem de sağlık çalışanı/profesyonellerinin karşılıklı kullanımı ile yeni ve bambaşka bir dünya yaratan sosyal ağlar üzerinde gerçekleşen sağlık iletişimi ile ilgili birtakım verilerle değerlendirme yapılan bu çalışmada tekil sosyal medya kullanıcısı olan öğrenciler ile görüşmeler yapılmıştır. Çünkü, internetin hızlı gelişimi ile birçok online içerikli sağlık siteleri/toplulukları ortaya çıkmış ve birçok 
hasta bu siteleri tedavileriyle ilgili bilgi almak ya da hastalıklarını araştırmak için ziyaret etmek amacıyla kullanmaktadır. Bu durumun gençler arasında daha yaygın olması da bu araştırmada üniversite öğrencileri ile görüşme yapmayı gerektirmiştir.

Sağlık bilgilerinin güvenilir bir içerikte sunulması çok önemlidir. Çünkü insanlar haber, hava durumu, film incelemeleri, alışveriş ve iş bilgileri için internette nasıl arama yapacaklarını bilseler de, sağlık ve medikal araştırmalar için gerekli ve yeterli düzeyde bilgi nadiren karşılarına çıkmaktadır. Çünkü araştırmaya başladıklarında zihinlerinde güvenilir bir marka veya portala inanma zorunlulukları bulunmamaktadır. $\mathrm{Bu}$ nedenle, insanlar genel bir haber web sitesinin veya bir e-ticaret sitesinin inanılırlığını değerlendirmeye yetecek kadar anlayışlı ve deneyimli olsalar da, günlük kullanım söz konusu olmayan sağlık web sitelerinde, genellikle yetersiz deneyim ve uzmanlığa sahiptirler. Bu, hayatlarında daha önce sağlık sorunları yaşamamış birçok genç sağlık bilgi arayıcısı birey için özellikle daha doğru bir tanımlama olabilmektedir (Eysenbach, 2008:124).

$\mathrm{Bu}$ çalışmanın araştırma sonuçları da sosyal medya araçlarının sağlık alanını dijital bir hale getirdiğini bir kez daha kanıtlamaktadır. Üniversite öğrencileri ve gençler her alanda olduğu gibi sağlık alanında da elektronik olarak belirli bir okuryazarlık seviyesine gelmiştir. Ancak dijital ortamlarda elde edilen sağlık bilgi ve kaynaklarının kullanımı sonucunda elde edilen neticelerin olumlu veya olumsuz bir etki yaratması tartışması başka bir çalışmanın konusudur. Burada niceliksel olarak kullanım ve yarar üzerine bir takım sonuçlara ulaşı1mıştır. Elde edilen sonuçlara göre ciddi oranda bir sosyal medya tüketimi söz konusudur. Sosyal medya araçları üzerinde sağlık içeriklerine ulaşma, kaynak tarama, kaynakları kullanma gibi birçok başlıkta artan bir eğilim söz konusudur. Yalnızca hasta olma durumunda değil sağlikla ilgili son güncel bilgileri takip etme, alandaki gelişmeler, tedaviye erişim, elde edilen sağlık bilgilerini değerlendirme, kaynaklar arasında yüksek/düşük kaliteli olanları ayırma gibi birçok tutum dijital sağlık alanında gelişim göstermektedir. 


\section{KAYNAKÇA}

Al-Bahrani, A., Patel,D., Sheridan\& B. J. (2017).EvaluatingTwitterandİtsİmpact on Student Learning in Principles of Economics Courses. TheJournal of EconomicEducation 48:4, p. 243-253.

Aygün, C.S. (2007). "İnternet ve Etik: Örnek Uygulama Alanı Olarak Sağlık İletişimi”, Mustafa Akgül (Ed.) Bilgi Toplumuna Doğru XII: Türkiye'de İnternet, Ankara: Nokta Ofset, s. 292-305.

Becerikli, S. Y.(2012). Sağlık İletişimi Çalışmalarında Alımlama Analizinin Kullanımı: Odak Grup Çalı̧̧ması Yoluyla Kamu Kampanyaları Ve Reklam Metinlerine İlişkin Çapraz Bir Okuma Pratiği. İstanbul Üniversitesi İletişim Fakültesi Dergisi, (43), 163-177.

Brownstein, J. S., Freifeld, C. C., \&Madoff, L. C. (2009). DigitalDiseaseDetection-Harnessingthe Web for PublicHealthSurveillance,New EnglandJournal of Medicine, 360(21), 2153-2157.

Chou, W. Y. S., Hunt, Y. M., Beckjord, E. B., Moser, R. P., \&Hesse, B. W. (2009). Social Media Usein the United States: Implications for HealthCommunication.Journal of MedicalInternet Research, 11(4).

Eysenbach, G. (2008). Credibility of HealthİnformationandDigital Media: New Perspectivesandİmplications for Youth. DigitalMedia, Youth, andCredibility, p. 123-154.

Flanagin, A. J., \&Metzger, M. J. (2008). DigitalMediaandYouth: UnparalleledOpportunityandUnprecedentedResponsibility. DigitalMedia, Youth, andCredibility, p. 5-27.

Fox, S., \&Jones, S. (2009, June). TheSocial Life of Healthİnformation. Washington, DC: Pew Internet \&American Life Project. Retrievedfrom http://www.pewinternet.org/ /media//Files/Reports/ 2009/PIP_Health_2009.pdf

Gencer, Z. T. (2017). Norman ve Skınner'ın E-Sağlık Okuryazarlığı Ölçeğinin Kültürel Uyarlaması İçin Geçerlilik ve Güvenilirlik Çalışması. İstanbul Üniversitesi İletişim Fakültesi Dergisi, (52), 131.

Karagöz, K. (2013). Yeni Medya Çağında Dönüşen Toplumsal Hareketler ve Dijital Aktivizm Hareketleri. İletişim ve Diplomasi, 1(1), 131-156.

Karimkhani, C., Connett, J., Boyers, L., Quest, T., \&Dellavalle, R. P. (2014). Dermatology on Instagram,Dermatology online journal, 20(7).

Korda, H., \&Itani, Z. (2013). Harnessing Social Media for HealthPromotionandBehaviorChange. HealthPromotionPractice, 14(1), 15-23.

Lupton, D. (2012). M-healthandHealthPromotion: TheDigitalCyborgandSurveillanceSociety. Social Theory\&Health, $10(3), 229-244$.

Montgomery, K. (2000). YouthandDigital Media: A PolicyResearchAgenda. Journal of AdolescentHealth, 27(2), 61-68.

Okay, A. (2007). Sağlık İletişimi, İstanbul: MediaCat Yayınları.

Smahel, D., Wright, M. F., \&Cernikova, M. (2015). Theimpact of digitalmedia on health: children'sperspectives. International journal of publichealth, 60(2), 131-137.

Şener, E., \& Samur, M. (2013). Sağlığı Geliştirici Bir Unsur Olarak Sosyal Medya: FacebooktaSağlık.Gümüşhane Üniversitesi Sağlık Bilimleri Dergisi, 2(4).

Tengilimoğlu, E., Parıltı, N. ve Yar, C. E. (2015). Hastane ve Hekim Seçiminde Sosyal Medyanın Kullanım Düzeyi: Ankara İli Örneği. İktisadi ve İdari Bilimler Fakültesi Dergisi, 17(2), 76-96.

Koçak, A. veBulduklu, Y. (2010). Sağlık İletişimi: Yaşlıların Televizyonda Yayınlanan Sağlık Programlarını İzleme Motivasyonları. Selçuk Üniversitesi İletişim Fakültesi Akademik Dergisi, 6(3), 5-17.

Thackeray, R., Neiger, B. L., Hanson, C. L., \&McKenzie, J. F. (2008). EnhancingPromotionalStrategiesWithin Social Marketing Programs: Use of Web 2.0 Social Media. HealthPromotionPractice, 9, 338-343.

Türk, G. D. (2013). Demokrasinin Dördüncü Kuvveti Yeni Medya Teknolojileri,XVIII. Türkiye’de İnternet Konferansı, INETD.

Vandewater, E. A., Rideout, V. J., Wartella, E. A., Huang, X., Lee, J. H., \&Shim, M. S. (2007). DigitalChildhood: Electronic Media andTechnologyUseAmongİnfants, Toddlers, andPreschoolers. Pediatrics, 119(5), e1006-e1015. 